\title{
FROM THE DESK OF EDITOR in CHIEF
}

(J Bangladesh Coll Phys Surg 2016; 34: 124)

Dear Fellows,

AssalamuAlaikum. We are stepping forward with timely publication of our beloved journal. I am truly thankful to the authors, the reviewers, the members of the editorial board, the office staffs, the press and all concerned. Our endeavor for further improvement continues and I would request our honored reviewers to help us with their comments within time. So that we would be able to give feedback to the authors in time and they would be encouraged to produce high quality articles. Meanwhile the editorial board is putting all out efforts to co-ordinate the whole process to make accurately timed publication of JBCPS. I am sure to have all your support thankfully. Thank you.

\author{
Prof. KhanAbul KalamAzad \\ Editor-in-Chief \\ Journal of BCPS
}

